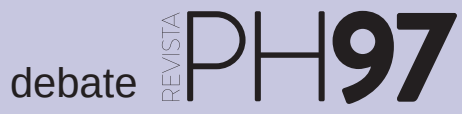

a debate El papel del patrimonio en las nuevas políticas para la cultura, la ciudad y el territorio: las agendas urbanas como marco de oportunidad

| coordinan Blanca del Espino Hidalgo, Rafael Merinero Rodríguez

\title{
Patrimonio y cultura: recursos para el desarrollo urbano. Málaga como laboratorio
}

Celia López-Bravo | Dpto. de Historia, Teoría y Composición Arquitectónica, U. de Sevilla

Daniel Navas-Carrillo | Dpto. de Urbanística y Ordenación del Territorio, U. de Sevilla

URL de la contribución <http://www.iaph.es/revistaph/index.php/revistaph/article/view/4402>

Málaga es una de las ciudades andaluzas cuyo análisis puede resultar de mayor interés para el debate planteado. No solo es, junto a La Coruña y Murcia, una de las tres únicas ciudades españolas que cuenta con Agenda Urbana, sino que la cultura entendida como producto turístico constituye desde hace más de veinte años uno de los protagonistas fundamentales del desarrollo urbano y económico de la ciudad.

Este hecho queda de manifiesto en el análisis de la extensa e innovadora trayectoria de la ciudad en materia de planificación estratégica participada. Este recorrido viene marcado por la redacción de dos Planes Estratégicos (PEM) y recientemente de la Estrategia Málaga 2020, los cuales quedan enmarcados en la iniciativa local del Centro de Investigaciones Estratégicas y de Desarrollo Económico y Social (CIEDES), fundación integrada por las principales instituciones y entidades sociales de la ciudad. El primer PEM (1992-1996) ya sitúa a la cultura como factor clave para el desarrollo futuro de la ciudad en su aspiración de convertirse en capital turística y de ocio europea (Línea Estratégica IV), ostentando un papel central en la oferta turística de la Costa del Sol. Buscando implementar un modelo urbano basado en el turismo cultural (GARCÍA PEÑA; TAPIA MARTINEZ, 2000: 137) se propone, entre otras medidas, la creación de una red de museos temáticos o la recuperación del centro histórico en su conjunto (Línea Estratégica $\mathrm{VI}$ ), así como la rehabilitación de otros bienes patrimoniales con potencial para uso turístico.

El segundo PEM (2006-2014), revisado en 2010 para adaptarlo al contexto de crisis económica, avanza en esta misma línea proponiendo "Málaga, ciudad de la cultura", como una de las cuatro líneas de debate, trans-

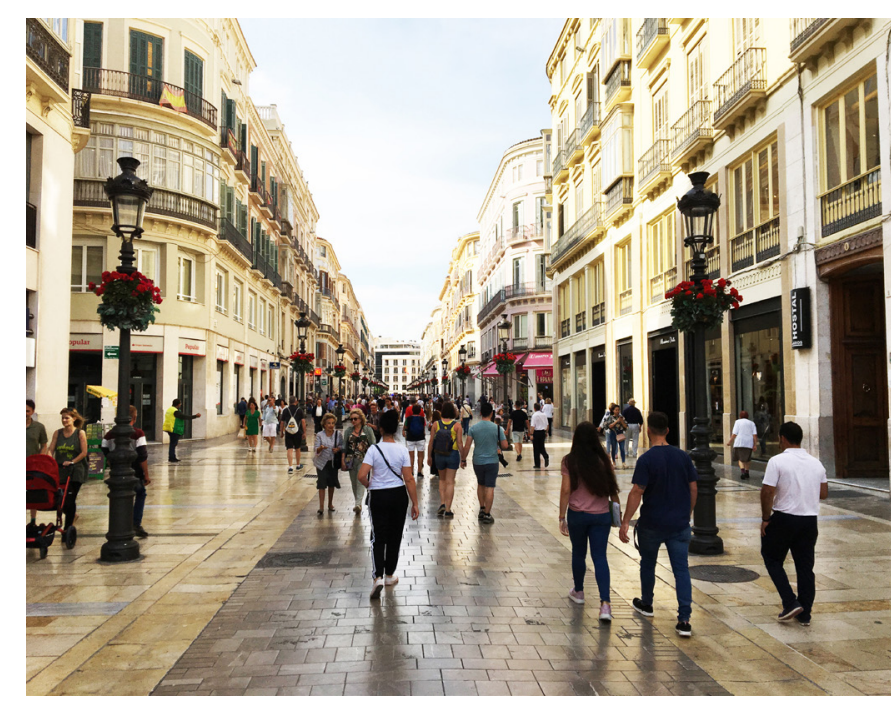

Estado actual calle Marqués de Larios tras su peatonalización en 2002, Málaga | foto Celia López-Bravo, Daniel Navas-Carrillos, 2019

formándose en la estrategia "La Málaga de Picasso, cultural y atractiva" que busca consolidar la cultura, también como núcleo de desarrollo social, potenciando el tejido e industria cultural, la imagen de calidad de la ciudad y la figura de Picasso, como vector de atracción de procesos de revalorización de su patrimonio (GARCíA PEÑA; TAPIA MARTINEZ, 2006: 142). Enmarcado en la Estrategia Europea Horizonte 2020, el último de los documentos estratégicos avanza, aún más si cabe, en el vínculo entre turismo y cultura. No obstante, al mismo tiempo que propone mejorar el atractivo internacional de la oferta cultural existente, reconoce por primera vez la necesidad de superar los límites del centro histórico, empleando la cultura también como vector de desarrollo de los barrios periféricos (GARCíA PEÑA; VEGA PÉREZ, 2017: 43). Al respecto, se puede mencionar la iniciativa implementada recientemente por el 
a debate El papel del patrimonio en las nuevas políticas para la cultura, la ciudad y el territorio: las agendas urbanas como marco de oportunidad

| coordinan Blanca del Espino Hidalgo, Rafael Merinero Rodríguez

Ayuntamiento para impulsar rutas culturales alternativas que permitan reconducir los flujos turísticos hacia otros puntos de la ciudad (JIMÉNEZ, 2018).

En paralelo cabe destacar la labor que el Observatorio de Medio Ambiente Urbano (OMAU) viene desarrollando en la evaluación y diagnóstico de la realidad urbano-territorial a través de la implementación de la Agenda 21 desde el año 2005. Este organismo autónomo, pero dependiente del Ayuntamiento, fue pionero en la redacción de la actual Agenda Urbana, ya que fue implementada en simultáneo a la aprobación de la Agenda 2030 para el Desarrollo Sostenible de Naciones Unidas. Recordemos que este documento incluye los 17 Objetivos de Desarrollo Sostenible a partir de los cuales se articula la Nueva Agenda Urbana (NACIONES UNIDAS, 2017), la cual no sería presentada hasta un año después. No obstante, como se reconoce desde el propio OMAU, la Agenda Urbana de Málaga no supone una modificación sustancial frente al modelo de análisis anterior basado en los indicadores de la Agenda 21 (MARÍN COTS, 2018: 43). Aunque incorpora aspectos vinculados con la escala territorial y la componente social debemos considerarlo, por tanto, heredero de los anteriores. Este hecho es incluso patente en la dualidad o ambigüedad de su denominación: "Agenda 21 de Málaga 2015, Agenda Urbana en la estrategia de sostenibilidad integrada 2020-2050".

Resulta paradójico que, pese el empleo de la cultura como vector central de la política y planificación estratégica en Málaga, la Agenda Urbana no haya incluido un conjunto significativo de parámetros destinados a cuantificar o cualificar el papel de esta en el desarrollo sostenible de la ciudad. A nuestro juicio condicionada por la trayectoria continuista mencionada, solo es posible identificar un indicador relacionado, la proximidad a centros culturales, ya incluido en los anteriores análisis. A pesar de esta circunstancia, no debemos pasar por alto aquellas líneas estratégicas que ponen el foco sobre la dimensión turística-cultural y sus consecuencias para la sostenibilidad del modelo urbano de Málaga. El documento claramente aboga por proteger los espacios cul- turales y elementos fundamentales de la imagen urbana y la memoria histórica, si bien, advierte sobre uno de los principales problemas a lo que empieza a enfrentarse la ciudad de Málaga: la saturación turística y la ruptura del equilibrio o la capacidad de carga entre visitantes y residentes (MARÍN COTS; BÁEZ MUÑOZ; JIMÉNEZ MELGAR, 2015: 67).

Hay que reconocer el avance significativo que las actuaciones desarrolladas con financiación del Fondo Europeo de Desarrollo Regional en el marco de la iniciativa comunitaria URBAN (1994-1999, 2000-2006 y 2007-2013) ha supuesto para la recuperación del centro histórico y, en última instancia, para la consecución de los objetivos del planeamiento estratégico anteriormente mencionado (ROYO-NARANJO; DEL ESPINO HIDALGO; PÉREZ-CANO; MOSQUERA-ADELL, 2015: 436-437). Y viceversa, haber contado con estos documentos marco ha permitido orientar la inversión a favor del modelo urbano propuesto. La evolución descrita pone en valor el papel que han representado los recursos culturales y patrimoniales en la promoción turística de la ciudad. Al tiempo muestra como el turismo ha sido motor de la recuperación patrimonial y consolidación de la actividad cultural. Véase el crecimiento exponencial de bienes protegidos, de museos y centros expositivos o empresas destinadas a la difusión cultural. No obstante, estamos ante un proceso con beneficios controvertidos (SILVA PÉREZ; FERNÁNDEZ SALINAS, 2017: 95). A la ya comentada concentración masiva de turistas y las dificultades que puede conllevar para el buen funcionamiento urbano, debemos sumar los posibles riesgos de gentrificación, o la pérdida del valor de autenticidad de un tejido originalmente residencial abogado a la tercerización, como consecuencia, entre otros, de la permisividad del Plan Especial de Protección y Reforma Interior del Centro Histórico de Málaga (AYUNTAMIENTO DE MALAGA, 2014).

Sin embargo, nos gustaría finalizar señalando algunas de las medidas que, al menos sobre el papel, se están tomando para intentar subsanar esta situación. La Estrategia Urbana Integrada Sostenible "Perchel 
a debate El papel del patrimonio en las nuevas políticas para la cultura, la ciudad y el territorio: las agendas urbanas como marco de oportunidad

| coordinan Blanca del Espino Hidalgo, Rafael Merinero Rodríguez

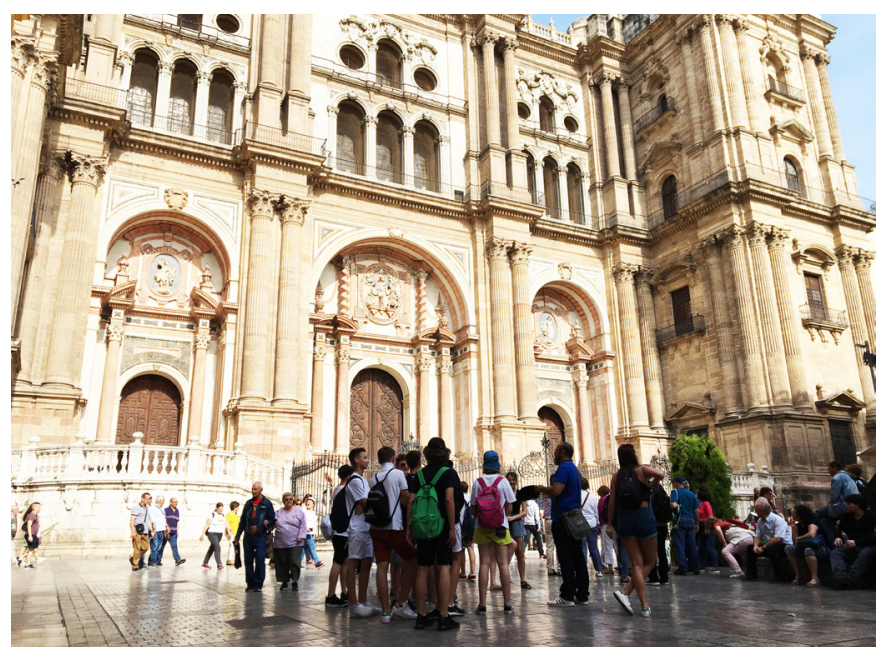

Concentración de grupos de turistas en el entorno de la Catedral de Málaga | foto Celia López-Bravo, Daniel Navas-Carrillos, 2019

Lagunillas" en cuya elaboración han participado tanto el OMAU como CIEDES, pone el acento sobre la necesidad de un desarrollo equilibrado del turismo cultural en el centro histórico, acompañado con la creación de un sistema de indicadores de evaluación del impacto del este (AYUNTAMIENTO DE MÁLAGA, 2015: 114). Entre otras actuaciones, propone la rehabilitación del patrimonio urbano en los arrabales del centro, buscando arraigar a la población que allí reside y atraiga a nuevos residentes, siendo a su vez generador de actividad económica y empleo.

\section{BIBLIOGRAFÍA}

- AYUNTAMIENTO DE MÁLAGA (2014) Plan Especial de Protección y Reforma Interior del Centro Histórico de Málaga. Documento de Avance. Málaga: Gerencia Municipal de Urbanismo, 2014

- AYUNTAMIENTO DE MÁLAGA (2015) Estrategia Urbana Integrada Sostenible "Perchel Lagunillas". Málaga: Servicio de Programas Europeos, 2015

- GARCÍA PEÑA, M. C.; TAPIA MARTINEZ, L. G. (2000) El proceso de transformación de una ciudad. Seguimiento y evaluación del Plan Estratégico de Málaga. Málaga: Fundación CIEDES, 2000

- GARCÍA PEÑA, M. C.; TAPIA MARTINEZ, L. G. (2006)
Málaga, Metropoli Abierta. Il Plan Estratégico de Málaga. Málaga: Fundación CIEDES, 2006

- GARCíA PEÑA, M. C; VEGA PÉREZ, J. E. (2017) Estrategia Málaga 2020. Prioridades para un trabajo conjunto. Málaga: Fundación CIEDES, 2017

- JIMÉNEZ, M. (2018) El Ayuntamiento ofrecerá rutas alternativas para evitar la saturación turística en el Centro. La opinión de Málaga, 8 de agosto de 2018 <https://www.laopiniondemalaga.es/malaga/2018/08/08/ ayuntamiento-ofrecera-rutas-alternativas evitar/1025556.html> [Consulta: 9/5/2019]

- MARÍN COTS, P. (2018) La agenda urbana de Málaga en la estrategia de sostenibilidad 2020-2050. En Ciudades en movimiento: avances y contradicciones en las políticas municipalistas ante las transiciones ecosociales. Madrid: Foro Transiciones.2018, pp. 9-100

- MARÍN COTS, P.; BÁEZ MUÑOZ, R.; JIMÉNEZ MELGAR, P. (2015) Agenda 21 de Málaga 2015, Agenda Urbana en la estrategia de sostenibilidad integrada 20202050. Málaga: Observatorio Medio Ambiente Urbano de Málaga, 2015

- NACIONES UNIDAS (2015) Transforming our World: The 2030 Agenda for Sustainable Development. Paris: Organización de las Naciones Unidas para la Educación, la Ciencia y la Cultura, 2015

- NACIONES UNIDAS (2017) Nueva Agenda Urbana. Conferencia de las Naciones Unidas sobre la Vivienda y el Desarrollo Urbano Sostenible (Hábitat III). Quito: Secretaría de Habitat III, 2017

- ROYO-NARANJO, L., DEL ESPINO HIDALGO, B., PÉREZ-CANO, T.; MOSQUERA-ADELL, E. (2015) Recuperación de centros históricos: Málaga, capital del turismo cultural urbano del s. XXI. En Impulso al desarrollo económico a través del turismo: VIII Jornadas de Investigación en Turismo. Sevilla: Iris-copy, 2015, pp. 429-450

- SILVA PÉREZ, R.; FERNÁNDEZ SALINAS, V. (2017) El patrimonio en la reinvención de Málaga. Agentes, instrumentos y estrategias. Investigaciones Geográficas, (67), 2017, pp. 81-100 